\title{
Effect of Secondary School Categorization on Value Addition in Public Secondary Schools Students in Kenya
}

\author{
Japhary Omari Nyangweso* \\ Kibabii University, PO Box 1699-50200 Bungoma \\ Julius K. Maiyo \\ Department of Educational Foundation, Planning and Management, \\ Kibabii University, P.o.box1699-50200 Bungoma \\ Robert Kati \\ Department of Science and Mathematics Education, \\ Kibabii University, P.o.box1699-50200 Bungoma
}

\begin{abstract}
Secondary schools in Kenya are categorized as national, extra-county, county, sub-county and private secondary schools. Students who excelled in K.C.S.E examination with a minimum grade of $\mathrm{C}+$ are allowed to pursue different courses in public and private universities. Others who scored $\mathrm{C}$ and $\mathrm{C}$ - grade joined diploma colleges. The paper sought to establish the effect of secondary school categorization on academic value addition in public secondary schools students at fourth form in Kenya. The scope of the study was limited to all the students from public secondary schools in the four counties of Kakamega, Bungoma, Busia, and Vihiga in Kenya. It was limited to randomly chosen sample size of 464 students, 58 principals, and 58 directors of studies from the 58 sampled out public secondary schools. Wellberg's (1981) theory of educational productivity was employed. The paper employed mixed methods and survey research design. Data collection instruments included questionnaires, interview schedules, focused group discussions and analysis of secondary data. Content validity was determined through subject matter expert review while reliability was determined through test-retest measures for consistency. Descriptive and inferential statistics were used to analyze data. Inferential one was the Kruskal Wallis test. The paper findings showed that value addition in public secondary schools in Kenya was not based on secondary school characteristics. The study concluded that irrespective of the score at KCPE and the category of public secondary school a student is admitted after KCPE, a student can add academic value. It was therefore recommended public secondary school characteristics which allowed student improvement at national and extra county school levels more than at sub-county and county secondary schools levels should be duplicated at county and sub county school levels.
\end{abstract}

Keywords: academic value addition, categorization, effect, Public secondary school, students

DOI: $10.7176 / \mathrm{JEP} / 10-33-12$

Publication date: November $30^{\text {th }} 2019$

\section{Introduction}

According to Taylor (2017), value-added progress is defined as measures used to estimate or quantify how much of a positive (or negative) effect individual teachers have on students' learning during the course of a given school year or period of years. He further argues that value-added progress uses sophisticated statistical algorithms and standardized-test results, combined with other information about students to determine a valueadded score for a teacher towards a given student. According to Taylor (2017), School administrators then use the score, usually in combination with classroom observations and other information about a teacher, to make decisions about tenure, compensation, or employment.

In a related study, Downes (2007) noted that the term 'value added' term in education is , most commonly used to describe the additional value schools bring to the learning outcomes of their students. This measures the contribution a school makes to the learning of its students that in turn enables judgments to be made about the schools' effectiveness and their ability to add value in terms of pupil attainment. Downes (2007) cited a useful definition of Value-added measures as those that attempt to indicate the educational value that the school adds over and above that which could be predicted given the backgrounds and prior attainments of the students within the school.

Downes (2007) found out that "value-added measures retained the subject scope of the test data on which they were based". For example, a value-added measure that was based on Year 6 reading results relative to Year 3 reading results for the same students was a measure of learning gained in that school for reading outcomes between those years. It measured the effectiveness of the school in teaching and preparing students over that time. It did not provide a measure of the effectiveness of the school as a whole.

Nguyen (2014) observed that value added score was also related to several school characteristics such as the 
school's admissions policy and its subject specialism.

In the context of Kenyan situation, the most desirable Kenyan secondary schools were elite government schools that admitted the best students from across the country. Mbiti (2015) noted that despite their reputations, research findings had revealed little evidence of positive impacts on learning outcomes for students who attended these schools, suggesting that their sterling reputations reflected the selection of students rather than their ability to generate value-added test-score gains. According to the researcher, elite, prestigious, and highly selective government secondary schools were common in education systems throughout the world. While such schools were perceived to be academically superior, whether their reputations simply reflected selection admissions or value-added learning was unclear. He further assert that if these schools delivered valued-added learning, the benefits might accrue heterogeneously to students depending on the characteristics of the student and the schooling environment.

\section{Methodology}

The paper employed mixed methods and survey research design. The study was conducted in four counties of Kakamega, Bungoma, Busia, and Vihiga in Kenya. The target population in this study was all the students from public secondary schools in the four counties. The sample size comprised of 464 students, 58 principals, and 58 directors of studies from the 58 sampled out public secondary schools. The study employed random and stratified sampling methods. Data collection instruments included questionnaires, interview schedules, focused group discussions and analysis of secondary data. Content validity was determined through subject matter expert review while reliability was determined through test-retest measures for consistency. Descriptive and inferential statistics were used to analyze data. Inferential one was the Kruskal Wallis test.

\section{Fig. 1 Area of study}

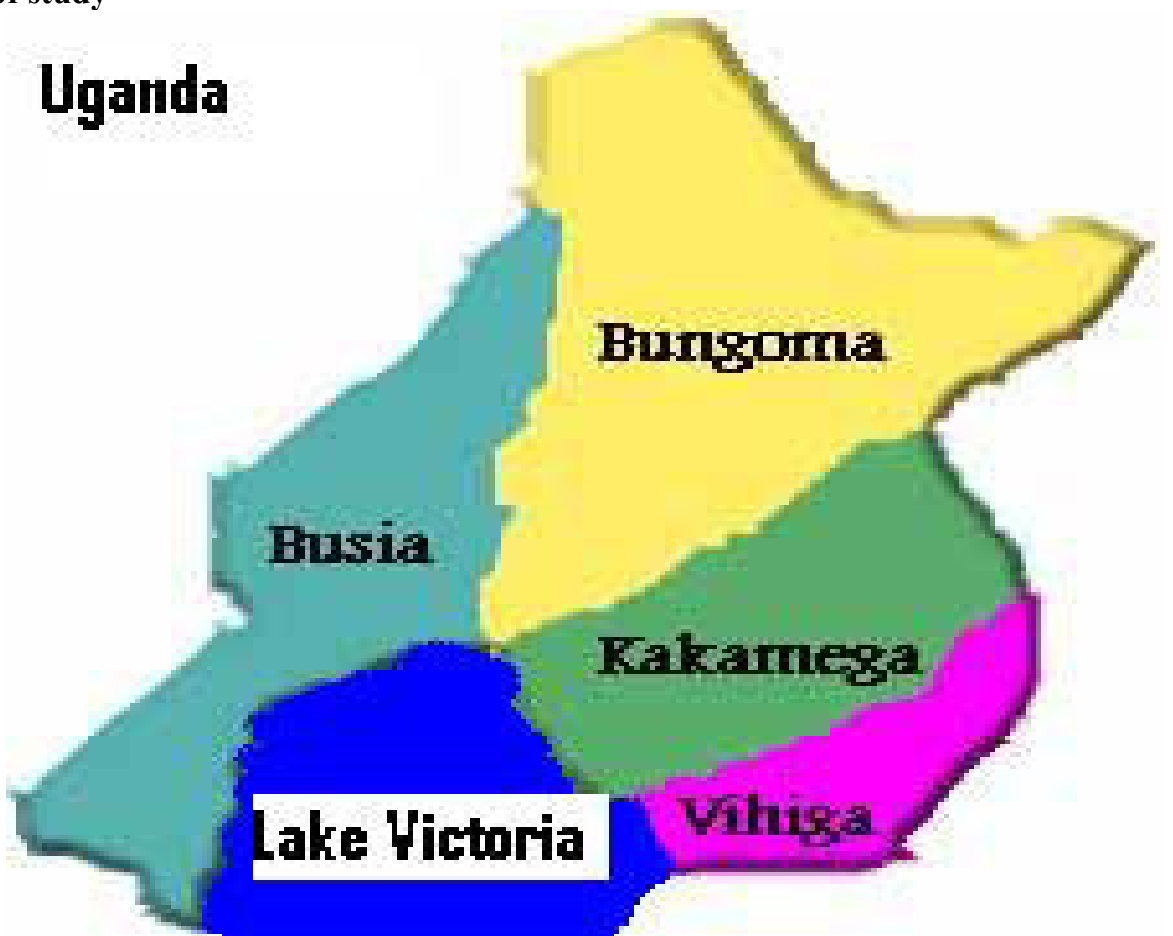

Figure 3.2: Map of the four counties of Kakamega, Bungoma, Busia and Vihiga

Source: Kenya government

\section{Results and discussions}

Table 1. Students' responses on value added progress

\begin{tabular}{lccccc}
\hline & Very similar & Similar & Different & Very different & Total \\
\hline Male & 28 & 52 & 108 & 74 & 262 \\
Female & 28 & 44 & 72 & 58 & 202 \\
Total & 56 & 96 & 180 & 132 & 464 \\
\hline
\end{tabular}

Source: Researcher (2019)

From table 1. Above, a sample of 464 public secondary student in their fourth form were asked to respond on their performance compared to their performance at KCPE. A total of 56 students responded that their performance was very similar to that at KCPE. They were 28 boys and 28 girls. Some 96 students, 52 boys and 
44 girls, said the performance in secondary schools was similar to their performance in primary schools. Another group of students, 180 of them, said it was different. They included 108 boys and 72 girls. Lastly, 132 students said it was very different. Of this 74 were boys and 58 were girls.

To establish whether there was a statistically significant difference in academic value added progress among students enrolled in the four different categories of public secondary schools in Kenya at their fourth form, a Kruskal Wallis test was run. Kruskal Wallis test ranks outputs are as shown in tables 2

Table 2. Ranks Table on students' responses on value addition

\begin{tabular}{llc}
\hline Category & $\mathrm{N}$ & Mean Rank \\
\hline Sub County & 190 & 256.49 \\
Extra County & 113 & 218.52 \\
County & 104 & 201.47 \\
National & 57 & 185 \\
Total & 464 & \\
\hline
\end{tabular}

\section{Source: Researcher (2019)}

The students' responses on value added progress while comparing performance at KCPE and performance in their fourth form were ranked and results shown in table 2. From these results, students from sub-county public secondary schools were ranked highest in asserting that their performance in KCPE were indeed different from those of high school. Their ranking was closely followed by that of students from extra county schools, then county schools and lastly the national school students who believed that the performance in KCPE was similar to that in high school. To find out if the difference in ranks was statistically significant, a chi-square statistic was established. This is shown in table 3.

Table 3.. Kruskal Wallis Test Statistics from students' responses on value added progress

\begin{tabular}{lc}
\hline Current performance compared to Performance at KCPE & \\
\hline Chi square & 15.101 \\
Df & 3 \\
Asymp. Sig & 0.075
\end{tabular}

\section{Source: Researche (2019)}

The null hypothesis which stated that "There was no statistically significant difference in academic value added progress among students in the four different categories of public secondary schools in Kenya" was thus accepted since the p-value was greater than 0.05 . A K]] $=$ ruskal-WallisH test showed that there was no statistically significant difference in academic value added progress among students in the four different categories of public bsecondary schools in Kenya with $\mathrm{X}^{2}(3)=15.101, p=0.075$, with a mean rank of 256.49 for Sub county schools, 218.52 for the extra county schools, 201.47 for county schools and 185.72 for national public secondary schools. This meant that value added progress was not a preserve of any category of a public secondary school but relied mostly on individual learners irrespective of the category of secondary school they were enrolled in. From the research findings it was discovered that categorization of public secondary schools alone was not an express indicator for value addition among public secondary students. This research findings were according to the students which were quite different from those of directors of studies and principals who thought otherwise.

These findings were collaborated by similar ones of Mbiti, (2015), who observed that even though most desirable Kenyan secondary schools were elite government schools that admitted the best students from across the country, research findings had revealed little evidence of positive impacts on learning outcomes for students who attended those schools. This was suggestive of the fact that their sterling academic reputations reflected the selection of students rather than their ability to generate value-added test-score gains, (Mbiti, 2015). According to the Mbiti (2015), elite, prestigious, and highly selective government secondary schools were common in education systems throughout the world. While such schools were perceived to be academically superior, whether their reputations simply reflected selection admissions or value-added learning was unclear. But the findings of this particular research on the relationship between secondary school categorization and value-added progress has made things clearer. Value added progress among public secondary school students did not wholly rely on the category of the school that a student was attending. The findings were also similar to those in Britain where a group of researchers noted that the value-added score published for all publicly funded secondary schools in England was an unreliable indicator of school performance. A substantial proportion of the betweenschool variation in the value-added score was accounted for by factors outside of the school's control. These factors included several pupil-related variables such as the proportion of pupils on free school meals, the authorized absence rate of pupils and the proportion of pupils from ethnic minority backgrounds. The valueadded score was also related to several school characteristics such as the school's admissions policy and its 
subject specialism, (Nguyen, 2014). The similarity of this research findings with those in other parts of the world made them more realistic and valid.

The findings from the principals and directors of studies were similar to the finding's students. The principals were of opinion that value added progress was independent of the category a student joined after KCPE. One principal of an extra county secondary school said that students in many neighboring public subcounty secondary schools were outshining those in extra county and national public secondary schools. "Our students in extra county schools and even national public secondary schools perform poorly in terms of valueadded progress compared to the students in sub-county schools. We have seen several quality grades from public day school students compared to grades some of our students who scored straight A grades at KCPE achieve," said one principal of an extra county public secondary school. The responses from the 58 high school principals on value added progress were as shown in table 4.

Value added progress at form four and at KCSE among public secondary school students relied heavily on the academic programs put in place by individual schools and the different internal characteristics in different public secondary schools. This might have been the reason why students in well-equipped schools where the research was conducted had improved performance compared to their entry behavior at KCPE. On the other hand, the directors of studies in public secondary schools with meagre learning and teaching resources attributed value addition in their students to determination by the learners and the sacrifice by their teachers. These categories of students worked harder to break away from the chains of poverty. A good number, about $10 \%$, of students who joined sub county public secondary with less than 200 marks in KCPE ended up adding value at KCSE despite their poor performance at KCPE.

On the extent to which the findings filled the research gap that would have existed, it was indeed observed that the findings of the research adequately filled the knowledge gap that existed. The previous research findings on value added progress among students fell short of outlining the effect of secondary school categorization on value addition in students' academic progress. The research findings of this study established that there was indeed no statistically significant difference in academic value added progress among students enrolled in the four different categories of public secondary schools in Kenya. This meant that value added progress did not rely heavily on public secondary school characteristics and the quality of the learners enrolled in the different categories of public secondary schools. From the research findings it was discovered that categorization of public secondary schools played a minimum role in determining value added progress among public secondary students in Kenya at form four and at KCSE. The knowledge gap which existed as to whether public secondary school's categorization had an effect on value added progress among Public secondary school students in Kenya at KCSE was thus filled. The findings went contrary to research findings of Eshiwani, (1993), who had observed that one of the factors that was considered in defining the quality of education in Kenya was the school quality. This was dictated by the category of the school which included National, extra-county, county, and sub-county and private schools. Once a learner joined a school, the school characteristics to some extent influenced his or her academic achievement. The quality of instructional process experienced by each learner determined the school quality and to a bigger extent value addition. School quality according to this study was not determined by the school category but rather by the internal organizations of individual schools. The findings of Eshiwani, (1993), were collaborated by those of Kadenyi (2013), who found out that categorization had made schools to have students with different entry behavior, different sources of funding, different teacher characteristics and different physical facilities. Kadenyi, (2013), asserted that national schools and especially those in urban centers had the best facilities including the best teachers. Some of those teachers set and examined at national level. This category of teachers tended to teach examination-oriented materials in order to appear in the top list of achievers when examination results were released. A positive value-added progress was thus realized. This might have been the reason why students in well-equipped schools where the research was conducted had improved performance compared to their entry behavior at KCPE. Equipping a school did not rely on the category of the school.

\section{Effect of public secondary schools' categorization on Value-Added Progress.}

On a four point rating scale of strongly agree, agree, disagree and strongly disagree, the 464 public secondary students were asked to give their ratings on a number of questions that were to give responses which were to determine their ratings on the effect of public secondary school categorization on value added progress among learners in public secondary schools that they were enrolled. Using a question in the questionnaire which required respondents to compare their performance in the category of public secondary schools they were learning with performance at KCPE, a summary of responses was as shown in the table 5 
Table 4.5. Students' responses on value added progress

\begin{tabular}{lccccc}
\hline & Very similar & Similar & Different & Very different & Total \\
\hline Male & 28 & 52 & 108 & 74 & 262 \\
Female & 28 & 44 & 72 & 58 & 202 \\
Total & 56 & 96 & 180 & 132 & 464 \\
\hline
\end{tabular}

Source: Researcher (2019)

From table 5 a sample of 464 public secondary student in their fourth form were asked to respond on their performance compared to their performance at KCPE. A total of 56 students responded that their performance was very similar to that at KCPE. They were 28 boys and 28 girls. Some 96 students, 52 boys and 44 girls, said the performance in secondary schools was similar to their performance in primary schools. Another group of students, 180 of them, said it was different. They included 108 boys and 72 girls. Lastly, 132 students said it was very different. Of this 74 were boys and 58 were girls.

To establish whether there was a statistically significant difference in academic value added progress among students enrolled in the four different categories of public secondary schools in Keny at their fourth form, a Kruskal Wallis test was run. Kruskal Wallis test ranks outputs are as shown in tables 5

Table 5. Ranks Table on students' responses on value addition

\begin{tabular}{lcc} 
Category & $\mathrm{N}$ & Mean Rank \\
\hline Sub County & 190 & 256.49 \\
Extra County & 113 & 218.52 \\
County & 104 & 201.47 \\
National & 57 & 185 \\
Total & 464 & \\
\hline
\end{tabular}

\section{Source: Researcher (2019)}

The students' responses on value added progress while comparing performance at KCPE and performance in their fourth form were ranked and results shown in table 5. From these results, students from sub-county public secondary schools were ranked highest in asserting that their performance in KCPE were indeed different from those of high school. Their ranking was closely followed by that of students from extra county schools, then county schools and lastly the national school students who believed that the performance in KCPE was similar to that in high school. To find out if the difference in ranks was statistically significant, a chi-square statistic was established. This is shown in table 6

Table 4.7. Kruskal Wallis Test Statistics from students' responses on value added progress

Current performance compared to Performance at KCPE

\begin{tabular}{lc}
\hline Chi square & 15.101 \\
Df & 3 \\
Asymp. Sig & 0.075 \\
\hline
\end{tabular}

\section{Source: Researcher (2019)}

The null hypothesis which stated that "There was no statistically significant difference in academic value added progress among students in the four different categories of public secondary schools in Kenya" was thus accepted since the $\mathrm{p}$-value was greater than 0.05 . A Kruskal-Wallis $\mathrm{H}$ test showed that there was no statistically significant difference in academic value added progress among students in the four different categories of public secondary schools in Kenya with $\chi^{2}(3)=15.101, p=0.075$, with a mean rank of 256.49 for Sub county schools, 218.52 for the extra county schools, 201.47 for county schools and 185.72 for national public secondary schools. This meant that value added progress was not a preserve of any category of a public secondary school but relied mostly on individual learners irrespective of the category of secondary school they were enrolled in. From the research findings it was discovered that categorization of public secondary schools alone was not an express indicator for value addition among public secondary students. This research findings were according to the students which were quite different from those of directors of studies and principals who thought otherwise.

These findings were collaborated by similar ones of Mbiti, (2015), who observed that even though most desirable Kenyan secondary schools were elite government schools that admitted the best students from across the country, research findings had revealed little evidence of positive impacts on learning outcomes for students who attended those schools. This was suggestive of the fact that their sterling academic reputations reflected the selection of students rather than their ability to generate value-added test-score gains, (Mbiti, 2015). According to the Mbiti (2015), elite, prestigious, and highly selective government secondary schools were common in education systems throughout the world. While such schools were perceived to be academically superior, whether their reputations simply reflected selection admissions or value-added learning was unclear. But the findings of this particular research on the relationship between secondary school categorization and value-added progress has made things clearer. Value added progress among public secondary school students did not wholly rely on the category of the school that a student was attending. The findings were also similar to those in Britain 
where a group of researchers noted that the value-added score published for all publicly funded secondary schools in England was an unreliable indicator of school performance. A substantial proportion of the betweenschool variation in the value-added score was accounted for by factors outside of the school's control. These factors included several pupil-related variables such as the proportion of pupils on free school meals, the authorized absence rate of pupils and the proportion of pupils from ethnic minority backgrounds. The valueadded score was also related to several school characteristics such as the school's admissions policy and its subject specialism, (Nguyen, 2014). The similarity of this research findings with those in other parts of the world made them more realistic and valid.

\section{Conclusion}

The findings showed that value addition in public secondary schools in Kenya was not based on secondary school characteristics. Students could add academic value in any category of public secondary school that they were enrolled. Individual student effort and internal academic organization in individual public secondary schools played a pivotal role in value added progress among learners. The paper concluded that irrespective of the score at KCPE and the category of public secondary school a student is admitted after KCPE, a student can add academic value.

\section{Recommendation}

The paper recommended that public secondary school characteristics which allowed student improvement at national and extra county school levels more than at sub-county and county secondary schools levels should be duplicated at county and sub county school levels.

\section{REFERENCES}

Downes, D. M., \& Vindurampulle, O. (2007). Value-added measures for school improvement. Education Policy and Research Division, Office for Education Policy and Innovation, Department of Education and Early Childhood Development.

Eshiwani, George (1993). Equity in access to secondary education in Kenya, Kenyatta University, Kenya.

Hicks, J. H., Kremer, M., Mbiti, I., \& Miguel, E. (2015). Vocational education in Kenya-A randomized evaluation. 3ie Grantee Final Report. New Delhi: International Initiative for Impact Evaluation (3ie).

Kadenyi (2013). Categorization of school: A sacrificial alter of academic excellence, Narok university college, Kenya.

Nguyen (2014). An Analysis of the Value Added by Secondary Schools in England: Is the Value Added Indicator of Any Value? Department of Economics, Management School, Lancaster University,

Taylor, E. W. (2017). Transformative learning theory. In Transformative learning meets bildung (pp. 17-29). Brill Sense. 